\title{
Milestones in the Curability of Pediatric Cancers
}

\author{
Melissa M. Hudson, St Jude Children's Research Hospital, Memphis, TN \\ Michael P. Link, Stanford University School of Medicine, Palo Alto, CA \\ Joseph V. Simone, Simone Consulting, Dunwoody, GA
}

Progress in the study and treatment of childhood cancer is arguably the most remarkable and rewarding story of cancer therapy in the past five decades. During this time, five-year survival rates have steadily increased and now exceed $80 \%$ in developed countries for all pediatric cancer sites (Fig 1). ${ }^{1}$ With the expectation of extended survival into adulthood for most childhood patients with cancer, clinicians and researchers have concentrated considerable attention on optimizing the quality of long-term survival for diseases that largely respond to cytotoxic agents and modalities injurious to normal tissues. In this recollection of that progress, we shall touch on advances common to many childhood cancers but focus primarily on childhood leukemia because it has been the bellwether of scientific and

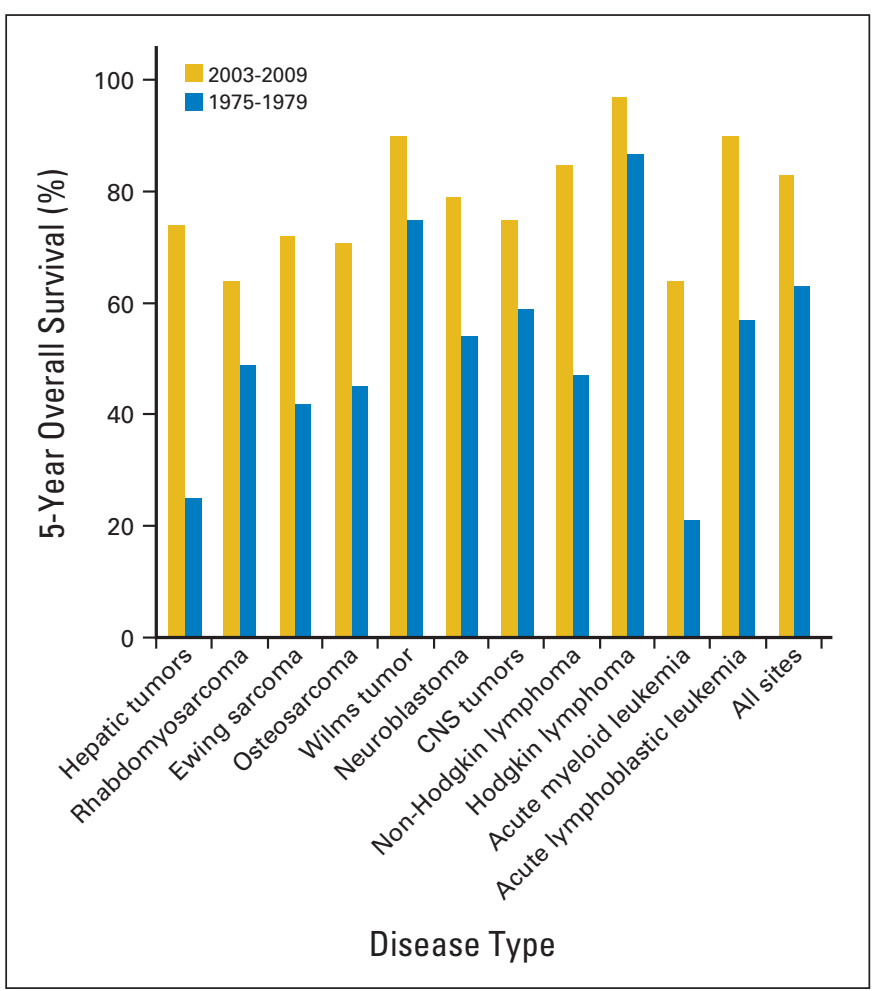

Fig 1. Five-year survival rates for two time periods for pediatric cancer diagnosed from birth to 19 years old. Five-year survival is presented for all sites (International Classification of Childhood Cancers) and specific histologic subtypes contrasting outcomes for children diagnosed between 1975 and 1979 with those diagnosed between 2003 and 2009. Data obtained from the National Cancer Institute SEER program from nine SEER registries based on patient cases observed through $2010 .^{1}$ therapeutic advances in many tumors, it encompasses many novel ideas in patient care during and after therapy, and it has influenced the study and treatment of adult cancers as well.

\section{Evolution of the Pediatric Acute Lymphoblastic Leukemia Treatment}

Table 1 summarizes factors motivating treatment evolution and progress in childhood acute lymphoblastic leukemia (ALL). Before 1950, childhood acute leukemia was not differentiated into ALL or acute myeloid leukemia. A diagnosis of childhood leukemia was uniformly fatal within an average period of 3 months. Death resulting from hemorrhage and severe infection was routine, and blood transfusions, the only treatment available at the time, were occasionally tried but did not help. Approximately $80 \%$ of these patient cases were later identified as having childhood ALL; that is still approximately the percentage of cases found today.

From 1950 to 1960 , dramatic changes in treatment occurred. Farber et $\mathrm{al}^{2}$ were the first to try chemotherapy in children with leukemia. Farber initially tested folic acid, because it was used to treat pernicious anemia and the bone marrow morphology of the two diseases looked similar. However, when folic acid seemed to make the leukemia worse, Farber decided to take the reverse approach and try aminopterin, an analog of methotrexate that interferes with folate metabolism. Also in this decade, George Hitchings and Gertrude Elion, who subsequently won the Nobel Prize, created 6mercaptopurine specifically to interfere with DNA metabolism. ${ }^{3}$ And cortisone, which was considered the new miracle drug, and prednisone were prescribed for many refractory diseases at the time, including leukemia. All these drugs were given as single agents that sometimes produced a transient response; ultimately, all patients died.

From 1958 to 1962, the first systematic combination chemotherapy trials for the treatment of leukemia were conducted primarily in children by Emil Frei and Jay Freireich of the National Cancer Institute, Donald Pinkel and James Holland from the Roswell Park Cancer Institute, Joseph Burchenal from the Memorial Sloan-Kettering Cancer Center, and others. The therapy was based primarily on two research findings: first, tuberculosis in humans that became resistant to single antibiotic therapy responded to triple-drug combinations; second, promising therapeutic studies using L1210 leukemia murine cell lines were tried in humans. ${ }^{4,5}$ These combinations resulted in remissions defined by transient improvement in symptoms (eg, stamina, appetite) and resolution of signs of bone marrow failure (eg, petechiae); but again, all patients eventually succumbed to the disease. 


\begin{tabular}{|c|c|c|}
\hline Decade & Treatment Progress During Decade & Factors Motivating Change \\
\hline 1960s & $\begin{array}{l}\text { Use of single-agent chemotherapy (methotrexate, } \\
\text { mercaptopurine, vincristine, asparaginase, } \\
\text { cyclophosphamide, daunorubicin, and cytarabine) } \\
\text { Introduction of combination chemotherapy treatment } \\
\text { protocols } \\
\text { Standardization of therapy phases (remission induction, } \\
\text { consolidation, CNS therapy, maintenance) }\end{array}$ & $\begin{array}{l}\text { Demonstration of antileukemic activity among agents interfering with } \\
\text { cellular metabolism } \\
\text { Recognition that single-agent therapy produced transient responses } \\
\text { Emulation of combination therapy approach successful in resistant } \\
\text { tuberculosis and preclinical mouse models } \\
\text { Appreciation of need for CNS-directed therapy with early use of } \\
\text { cranial and craniospinal irradiation }\end{array}$ \\
\hline 1970s & $\begin{array}{l}\text { Integration of anthracyclines in therapy protocols for high- } \\
\text { risk ALL } \\
\text { Demonstration of improved outcomes with use of therapy } \\
\text { intensification and delayed intensification } \\
\text { Reduction in use of spinal irradiation for CNS }\end{array}$ & $\begin{array}{l}\text { Recognition of diverse ALL pathobiology and outcomes } \\
\text { Appreciation of clinical factors that influence treatment outcomes } \\
\text { (age at diagnosis, initial leukocyte count, response to treatment) } \\
\text { Identification of pathobiologic differences in ALL that influence } \\
\text { outcome (immunophenotype, cytogenetics, chromosomal } \\
\text { translocations, chromosomal ploidy) } \\
\text { Demonstration of comparable outcomes using craniospinal irradiation } \\
\text { and cranial irradiation plus intrathecal chemotherapy }\end{array}$ \\
\hline 1980s & $\begin{array}{l}\text { Integration of asparaginase intensification in therapy } \\
\text { protocols for high-risk ALL } \\
\text { Restriction of epipodophyllotoxin use for most children with } \\
\text { ALL } \\
\text { Reduction in use of cranial irradiation therapy for CNS- } \\
\text { negative ALL }\end{array}$ & $\begin{array}{l}\text { Appreciation of delayed neurocognitive and neuroendocrine toxicities } \\
\text { after cranial irradiation } \\
\text { Recognition of treatment-related acute myeloid leukemia associated } \\
\text { with epipodophyllotoxins } \\
\text { Demonstration that intensified (triple) intrathecal chemotherapy could } \\
\text { sustain CNS remissions without the use of cranial irradiation in } \\
\text { patients with standard-risk ALL }\end{array}$ \\
\hline 1990s & $\begin{array}{l}\text { Introduction of imatinib for Philadelphia } \\
\text { chromosome-positive ALL } \\
\text { Integration of dexamethasone in induction therapy protocols } \\
\text { Reduction in dose and use of preventive cranial irradiation } \\
\text { Recognition of role of host pharmacogenomics in } \\
\text { chemotherapy-related toxicity and ALL response } \\
\text { Implementation of risk-stratified treatment protocols on the } \\
\text { basis of ALL pathobiology }\end{array}$ & $\begin{array}{l}\text { Identification of novel antileukemia drug targets on the basis of } \\
\text { molecular and cellular changes stimulating leukemia development } \\
\text { (eg, BCR-ABL) } \\
\text { Recognition of radiation-related subsequent neoplasms } \\
\text { Recognition of dose-related risk of anthracycline cardiotoxicity } \\
\text { Recognition of dose-related risk of cyclophosphamide gonadal } \\
\text { toxicity } \\
\text { Demonstration of superiority of dexamethasone compared with } \\
\text { prednisone in preventing CNS relapse }\end{array}$ \\
\hline $2000 s$ & $\begin{array}{l}\text { Personalization of therapy related to early treatment } \\
\text { response (minimal residual disease) } \\
\text { Elimination of use of cranial irradiation for most children } \\
\text { with ALL } \\
\text { Investigation (ongoing) of molecular targets for drug } \\
\text { development }\end{array}$ & $\begin{array}{l}\text { Demonstration of prognostic significance of minimal residual disease } \\
\text { Recognition of role of pharmacogenomics in treatment response and } \\
\text { acute/delayed toxicities } \\
\text { Identification of novel leukemia subtypes on the basis of alterations } \\
\text { in cellular signaling }\end{array}$ \\
\hline
\end{tabular}

From 1960 to 1967, physicians formulated diagnostic criteria for childhood leukemia. They designated continuous complete remission as the gold standard of success, and established the disease subtypes by ordinary light microscopy. At the time, there were several obstacles to effective therapy: the disease was widespread at diagnosis; localized therapy was basically ineffective; and both the disease and the therapy damaged the bone marrow, which frightened the medical community. And of course, physicians were ignorant of the pathogenesis of the disease and why drugs succeeded or failed, which remains a problem today.

There were additional obstacles to cure. First of all, there was a fear of chemotherapy, and some eminent hematologists were the most antagonistic toward chemotherapy. Many hematologists in large medical centers were strongly opposed to giving chemotherapy (often referred to as poisoning children), and a misguided protectionism to shield children from further suffering was the prevailing attitude. There was also a distrust of clinical trials and protocols, which were dubbed cookbook medicine by some physicians who did not want to be told how to treat their patients. Pessimism and provincialism, especially in medical schools, were also obstacles to cure. St Jude Children's Research Hospital and other institutes were looked down on because they were not in the academic mainstream, which in the long run turned out to be an asset rather than a liability.

Despite these obstacles, amazing progress was made from 1960 to 1967. Vincristine, asparaginase, cyclophosphamide, daunorubicin, and cytarabine were all introduced into clinical use in that narrow window of time. The importance of the phases of therapy-remission induction, intensification, consolidation, CNS therapy, maintenance, and so forth-was beginning to be recognized. CNS involvement became a major problem with achievement of prolonged bone marrow remissions. On the basis of mouse studies, Pinkel et al elucidated the concept of occult meningeal leukemia and the importance of presymptomatic CNS-directed therapy. ${ }^{6-8}$ Without specific CNS therapy, CNS relapse preceded bone marrow relapse in an increasingly higher proportion of patients.

Considering these observations, the early St Jude Total Therapy studies culminated in the pivotal Study V that changed the direction of the treatment of childhood leukemia. ${ }^{6,9}$ The study design called for the maximum tolerated dose of chemotherapy, aggressive supportive care, and better CNS prophylaxis. Prednisone and vincristine were administered as induction therapy followed by an intensive phase of high-dose 6-mercaptopurine, methotrexate, and cyclophosphamide given intravenously during a 7-day period. A lymphomacidal dose of 2,400 cGy cranial radiation plus intrathecal methotrexate was administered during 2 1/2 weeks. Patients received 6-mercaptopurine once per day, methotrexate and cyclophosphamide once per week, and prednisone and vincristine twice every 10 weeks. With this approach, which is similar to the treatment model used today, 31 of 35 consecutive patients attained complete remission and received all phases of 
therapy. Not a single patient relapsed in the first 6 months, and $50 \%$ of patients were long-term survivors in continuous complete remission. ${ }^{10}$ Subsequent trials during the 1970 s established the benefit of delayed intensification therapy after remission induction and further advanced long-term survival rates to almost $70 \% .^{11-14}$

\section{Developing the Risk-Directed Therapy Paradigm}

With the establishment of an effective portfolio of agents, clinical trials in the last three decades have focused on risk stratification and application of intensified regimens to targeted subsets of patients to advance survival rates and reduce treatment-related morbidity and mortality. Strategies for risk categorization during this time have been based on age at diagnosis, initial leukocyte count, leukemic cell genetics, and initial response to treatment. ${ }^{15}$ Progress in the understanding of ALL pathobiology permitted more informed risk assessment using immunophenotyping, cytogenetics, immunophenotype-specific chromosomal translocations, and modal chromosomal number (ploidy). Survival outcomes for childhood ALL in the last four decades derived from the SEER program data from 1975 to 2009 illustrate the collective success of these efforts nationwide (Fig 1), with results from specific groups demonstrating even better outcomes. ${ }^{16-18}$

In recent years, initial response to treatment as determined by minimal residual disease has provided an assessment of drug sensitivity as well as host pharmacodynamics and pharmacogenomics and treatment adherence; this technology has permitted more precise risk stratification. ${ }^{15}$ Characterization of the molecular and cellular changes stimulating cancer development elucidated novel targets for anticancer drug development. The first among these was the identification of the Philadelphia chromosome in ALL, ${ }^{19}$ which ultimately led to the successful use of targeted therapy with imatinib, a selective inhibitor of the BCR-ABL1 tyrosine kinase. ${ }^{20}$ Genetic expression profiling, mutational analyses, and genome-wide analyses have enabled recent discoveries of novel leukemia subtypes with alterations in cell signaling that may benefit from targeted therapy. ${ }^{21-24}$

\section{Late Health Outcomes As a Driver of Therapy Evolution}

Observational studies of late health outcomes among long-term survivors of ALL have been a major impetus for therapy change. Initially, concerns regarding delayed neurocognitive $e^{25-27}$ and neuroendocrine dysfunction ${ }^{28-33}$ associated with cranial irradiation motivated several cooperative group trials that established that intensification of intrathecal chemotherapy with either methotrexate alone or methotrexate in combination with hydrocortisone and cytarabine could sustain CNS remissions without the use of cranial radiation. ${ }^{34-36}$ These data, combined with evidence of the superiority of dexamethasone compared with prednisone ${ }^{37}$ in preventing CNS relapse were influential in the design of recent trials that have eliminated cranial irradiation. ${ }^{18}$ Recognition of treatment-related subsequent neoplasm, such as radiation-related CNS malignancies ${ }^{38-41}$ and epipodophyllotoxin-associated secondary leukemia, ${ }^{42-46}$ has also been a powerful stimulus for restricting the use of these modalities in contemporary regimens.

Appreciation of a pediatric-specific threshold for anthracycline cardiotoxicity among children with $\mathrm{ALL}^{47-51}$ prompted evaluation of the cardioprotectant dexrazoxane and continuous infusion anthracycline administration in first-line trials. ${ }^{52-54}$ Whereas adult studies demonstrated an excess risk of anthracycline-induced congestive heart failure after treatment with cumulative doses of $550 \mathrm{mg} / \mathrm{m}^{2}$ or higher, ${ }^{55}$ children are more vulnerable to this complication at lower cumulative doses and debate continues regarding whether any dose is truly safe. ${ }^{56-58}$ Lacking echocardiographic evidence of long-term benefit of preventive measures, anthracycline doses are proactively restricted in contemporary regimens with higher cumulative doses reserved for children and adolescents with unfavorable risk disease features. Similarly, a risk-adapted approach guides the dosing of cyclophosphamide in an effort to optimize leukemic response and preserve fertility of long-term survivors, especially for boys, who are more susceptible to alkylating agent germ-cell injury than girls. ${ }^{59}$

The achievement of extended survival into adulthood for most children with ALL produced compelling evidence of the scope and severity of treatment-related adverse effects and their contribution to premature mortality and reduced quality of survival. ${ }^{60-65}$ These observations motivated investigations aiming to more accurately characterize risk profiles for adverse outcomes to facilitate risk-adapted treatment assignment (when possible) and timely diagnosis and intervention to prevent or remediate morbidity. ${ }^{66}$ Numerous studies have elucidated factors influencing the risk for neurocognitive, ${ }^{67-71}$ skeletal, ${ }^{71-83}$ cardiovascular and metabolic, ${ }^{31,50,56,57,84-86}$ and neoplastic complications ${ }^{38,39,41-43,45,46,87}$ related to the individual patient as well as sociodemographic status and cancer history. An active area of investigation in more recent years is the study of how genetic variations influence not only response to antileukemia therapy ${ }^{88,89}$ but also the risk of long-term and late cancer treatment-related toxicity. ${ }^{56,69,81}$ This research has focused largely on single nucleotide polymorphisms that affect drug disposition and normal tissue recovery from cytotoxic therapy. Findings from this line of study may ultimately permit more precise risk characterization that can be used to guide treatment planning and toxicity monitoring.

\section{Translating Findings of Outcomes Studies Into Survivorship Care}

Despite substantial research linking specific cancer therapies with adverse outcomes, limited high-quality research exists evaluating the risks, benefits, and harms of health screening and health promoting interventions among high-risk groups. Given the relatively small numbers of pediatric cancer survivors, their variable access to pediatric late effects research programs, and the delayed time to presentation of many outcomes, implementation of randomized controlled trials in asymptomatic survivors to assess the impact of screening on morbidity and mortality associated with a specific late effect is challenging and often not feasible. Notwithstanding these deficiencies, clinical practice guidelines for the management of asymptomatic long-term survivors of childhood, adolescent, and young adult cancers have been organized by several groups to standardize the care of this medically vulnerable and growing population. Recommendations have been developed from a hybrid approach that uses evidence from the extant literature linking late effects with therapeutic exposures and formulates screening recommendations on the basis of the clinical experience of late effects experts, matching the magnitude of the risk with the intensity of screening. ${ }^{90,91}$ The currently available clinical practice guidelines have been useful in identifying research priorities to address knowledge gaps in survivorship care such as who may benefit from screening, the time to initiate screening, the frequency of screening, and the optimal modality of screening. ${ }^{92,93}$ 
Standardizing survivor care also enhances opportunities for discovery of novel and unanticipated treatment effects and provides critical information to guide the development of health-promoting interventions. Consistency of cardiac screening among a wellcharacterized cohort of children with ALL advanced understanding of the pathophysiology of anthracycline cardiotoxicity ${ }^{48-50}$ and informed clinical trials to prevent and remediate this complication. $^{53,54,94,95}$ Proactive screening of neurocognitive functioning has also been instrumental in discerning outcomes of evolving CNSdirected therapy among children and adolescents ${ }^{68,69,96-98}$ and guiding interventions ${ }^{99,100}$ to optimize their educational and vocational achievement. With increasing numbers of adults treated for ALL during childhood, the challenge will be to understand how cancer treatment impacts natural organ senescence and translate this knowledge into interventions to promote healthy aging.

\section{Challenges to Achieving Future Progress}

The treatment paradigm that produced long-term disease-free survival in childhood ALL has been embraced as the standard for all pediatric cancers and continues to be highly supported by physicians, patients, and their families. Major factors in the success of therapy for pediatric cancer care are a multidisciplinary team approach and a preference for delivery of therapy in the context of a clinical trial. A fundamental tenet of these trials is the integration of biologic and therapeutic aims facilitated through the collection of tumor tissue. This factor has contributed substantially to advancing understanding about the heterogeneity of pediatric cancers across and within histologic subtypes and guided the development of risk-stratified therapy for a variety of hematologic and solid pediatric malignancies. ${ }^{15,101-104}$ For example, treatment planning for children with acute myeloid leukemia, ${ }^{104}$ non-Hodgkin lymphoma, ${ }^{105}$ Wilms tumor, ${ }^{106}$ neuroblastoma, ${ }^{101,102}$ and rhabdomyosarcoma ${ }^{107,108}$ routinely considers biologic factors (eg, histology, grade of tumor differentiation, DNA ploidy, chromosomal alterations, MYCN oncogene status). In neuroblastoma, international collaboration has permitted characterization of highly prognostic pretreatment clinical and biologic features that will facilitate the comparison of future risk-based clinical trials. ${ }^{102}$ In addition, clinicopathologic and biologic studies have identified prominent pathways (eg, FLT3, tropomyosin-related kinase B, vascular endothelial growth factor) $)^{109-111}$ and surface markers (eg, antiGD2) ${ }^{112}$ in malignant cells that have enabled the development of targeted therapies that are in use or under investigation.

Ongoing biologic research aims to identify novel therapeutic targets by clarifying the molecular drivers of disease at diagnosis and how these may change at relapse. Following the paradigm that benefitted patients with ALL with Philadelphia chromosome-positive ALL with the use of tyrosine kinase inhibitor of BCR-ABL1, a variety of molecular targets for pediatric malignancies are under investigation. ${ }^{113-115}$ This burgeoning area of research may ultimately guide the development of effective therapies with a lower risk of normal tissue injury. However, the undertaking of such studies in pediatric patients with cancer faces challenges on several fronts. First, the relative rarity of pediatric cancer reduces the priority assigned for new agent research and development by the pharmaceutical industry and the National Cancer Institute. ${ }^{116}$ Likewise, the biologic diversity between and within histologic subtypes limits the feasibility of recruitment of sufficient patient numbers to ascertain statistically powerful outcomes. Cooperative group and international collaboration will undoubtedly be needed for many diseases to establish treatment efficacy for new agents and accumulate the evidence required for their regulatory approval. Integrating targeted agents into first-line therapies will also require innovative clinical trial designs that consider the disease-free outcomes achieved with established cytotoxic treatment approaches as well as the potential for reduction in adverse events known to compromise quality and duration of survival. Clinicians will also have to contend with the ethical dilemma of testing novel regimens substituting targeted, presumably less toxic, agents for cytotoxic agents included in highly successful treatment approaches.

Appreciation of the unintended consequences of historic treatment approaches has engendered the commitment by pediatric investigators to continue systematic documentation of adverse health outcomes among childhood cancer survivors treated with contemporary therapy. Consequently, clinical trial funding must extend beyond the therapeutic objectives to include evaluation of late effects. Research characterizing genetic predispositions associated with increased vulnerability to acute and late treatment-related toxicity may guide the delivery of safer personalized therapy in the future. In this regard, researchers of pediatric ALL have completed pioneering investigations that have established correlations between genetic variations influencing antileukemic drug metabolism and distribution that contribute to treatment response, acute toxicity, and risk of late effects. ${ }^{69,72,81,89,117-119}$ Similar investigations involving diverse pediatric malignancies are exploring the genetic risk factors underlying other adverse outcomes such as cardiomyopathy and obesity. ${ }^{56,86,120,121}$ These efforts will be critical to defining the optimal therapeutic approach that balances the attainment of cancer-free survival with prevention of long-term and late treatment toxicities, particularly life-threatening toxicities.

\section{AUTHORS' DISCLOSURES OF POTENTIAL CONFLICTS OF INTEREST}

The author(s) indicated no potential conflicts of interest.

\section{AUTHOR CONTRIBUTIONS}

Manuscript writing: All authors

Final approval of manuscript: All authors

\section{REFERENCES}

1. Ward $E$, Desantis $C$, Robbins $A$, et al: Childhood and adolescent cancer statistics, 2014. CA Cancer J Clin [epub ahead of print on January 31, 2014]

2. Djerassi I, Farber $S$, Abir $E$, et al: Continuous infusion of methotrexate in children with acute leukemia. Cancer 20:233-242, 1967

3. Skipper HE, Thomson JR, Elion GB, et al: Observations on the anticancer activity of 6-mercaptopurine. Cancer Res 14:294-298, 1954

4. Goldman ID: A model system for the study of heteroexchange diffusion: Methotrexate-folate interactions in L1210 leukemia and Ehrlich ascites tumor cells. Biochim Biophys Acta 233:624-634, 1971

5. Shackney SE: A computer model for tumor growth and chemotherapy, and its application to L1210 leukemia treated with cytosine arabinoside (NSC63878). Cancer Chemother Rep 54:399-429, 1970

6. Aur RJ, Simone J, Hustu HO, et al: Central nervous system therapy and combination chemotherapy of childhood lymphocytic leukemia. Blood 37:272281,1971

7. Hustu HO, Aur RJ, Verzosa MS, et al: Prevention of central nervous system leukemia by irradiation. Cancer 32:585-597, 1973

8. Simone J, Pinkel D: Rationale and results of combination chemotherapy and central nervous system irradiation in acute lymphocytic leukemia. Bibl Haematol 39:1068-1073, 1973

9. Pinkel D, Simone J, Hustu HO, et al: Nine years' experience with "total therapy" of childhood acute lymphocytic leukemia. Pediatrics 50:246-251, 1972

10. Aur RJ, Simone JV, Hustu HO, et al: A comparative study of central nervous system irradiation and intensive chemotherapy early in remission of childhood acute lymphocytic leukemia. Cancer 29:381-391, 1972 
11. Henze G, Langermann $H J$, Brämswig J, et al: The BFM $76 / 79$ acute lymphoblastic leukemia therapy study [in German]. Klin Padiatr 193:145-154, 1981

12. Ritter J, Creutzig U, Reiter A, et al: Childhood leukemia: Cooperative Berlin-Frankfurt-Münster trials in the Federal Republic of Germany. J Cancer Res Clin Oncol 116:100-103, 1990

13. Sallan SE, Hitchcock-Bryan S, Gelber R, et al: Influence of intensive asparaginase in the treatment of childhood non-T-cell acute lymphoblastic leukemia. Cancer Res 43:5601-5607, 1983

14. Tubergen DG, Gilchrist GS, O'Brien RT, et al: Improved outcome with delayed intensification for children with acute lymphoblastic leukemia and intermediate presenting features: A Children's Cancer Group phase III trial. J Clin Oncol 11:527-537, 1993

15. Pui $\mathrm{CH}$, Mullighan CG, Evans WE, et al: Pediatric acute lymphoblastic leukemia: Where are we going and how do we get there? Blood 120:1165-1174, 2012

16. Moghrabi A, Levy DE, Asselin B, et al: Results of the Dana-Farber Cancer Institute ALL Consortium Protocol 95-01 for children with acute lymphoblastic leukemia. Blood 109:896-904, 2007

17. Möricke A, Reiter A, Zimmermann $M$, et al: Risk-adjusted therapy of acute lymphoblastic leukemia can decrease treatment burden and improve survival: Treatment results of 2169 unselected pediatric and adolescent patients enrolled in the trial ALL-BFM 95. Blood 111:4477-4489, 2008

18. Pui $\mathrm{CH}$, Campana $\mathrm{D}$, Pei $\mathrm{D}$, et al: Treating childhood acute lymphoblastic leukemia without cranial irradiation. N Engl J Med 360:2730-2741, 2009

19. Propp S, Lizzi FA: Philadelphia chromosome in acute lymphocytic leukemia. Blood 36:353-360, 1970

20. Schultz KR, Bowman WP, Aledo $A$, et al: Improved early event-free survival with imatinib in Philadelphia chromosome-positive acute lymphoblastic leukemia: A Children's Oncology Group study. J Clin Oncol 27:5175-5181, 2009

21. Den Boer $M L$, van Slegtenhorst $M$, De Menezes $R X$, et al: A subtype of childhood acute lymphoblastic leukaemia with poor treatment outcome: A genome-wide classification study. Lancet Oncol 10:125-134, 2009

22. Holmfeldt L, Wei L, Diaz-Flores $E$, et al: The genomic landscape of hypodiploid acute lymphoblastic leukemia. Nat Genet 45:242-252, 2013

23. Mullighan CG, Su X, Zhang J, et al: Deletion of IKZF1 and prognosis in acute lymphoblastic leukemia. N Engl J Med 360:470-480, 2009

24. Roberts KG, Morin RD, Zhang J, et al: Genetic alterations activating kinase and cytokine receptor signaling in high-risk acute lymphoblastic leukemia. Cancer Cell 22:153-166, 2012

25. Clarke M, Gaynon P, Hann I, et al: CNS-directed therapy for childhood acute lymphoblastic leukemia: Childhood ALL Collaborative Group overview of 43 randomized trials. J Clin Oncol 21:1798-1809, 2003

26. Mulhern RK, Fairclough D, Ochs J: A prospective comparison of neuropsychologic performance of children surviving leukemia who received 18-Gy, 24-Gy, or no cranial irradiation. J Clin Oncol 9:1348-1356, 1991

27. Ochs J, Mulhern R, Fairclough D, et al: Comparison of neuropsychologic functioning and clinical indicators of neurotoxicity in long-term survivors of childhood leukemia given cranial radiation or parenteral methotrexate: A prospective study. J Clin Oncol 9:145-151, 1991

28. Dalton VK, Rue M, Silverman LB, et al: Height and weight in children treated for acute lymphoblastic leukemia: Relationship to CNS treatment. J Clin Oncol 21:2953-2960, 2003

29. Didcock $E$, Davies HA, Didi $M$, et al: Pubertal growth in young adult survivors of childhood leukemia. J Clin Oncol 13:2503-2507, 1995

30. Garmey EG, Liu Q, Sklar CA, et al: Longitudinal changes in obesity and body mass index among adult survivors of childhood acute lymphoblastic leukemia: A report from the Childhood Cancer Survivor Study. J Clin Oncol 26:4639-4645, 2008

31. Razzouk $\mathrm{BI}$, Rose SR, Hongeng $\mathrm{S}$, et al: Obesity in survivors of childhood acute lymphoblastic leukemia and lymphoma. J Clin Oncol 25:1183-1189, 2007

32. Schell MJ, Ochs JJ, Schriock EA, et al: A method of predicting adult height and obesity in long-term survivors of childhood acute lymphoblastic leukemia. J Clin Oncol 10:128-133, 1992

33. Schriock EA, Schell MJ, Carter M, et al: Abnormal growth patterns and adult short stature in 115 long-term survivors of childhood leukemia. J Clin Oncol 9:400-405, 1991

34. Littman $P$, Coccia $P$, Bleyer WA, et al: Central nervous system (CNS) prophylaxis in children with low risk acute lymphoblastic leukemia (ALL). Int J Radiat Oncol Biol Phys 13:1443-1449, 1987

35. Sullivan MP, Chen T, Dyment PG, et al: Equivalence of intrathecal chemotherapy and radiotherapy as central nervous system prophylaxis in children with acute lymphatic leukemia: A Pediatric Oncology Group study. Blood 60:948-958, 1982
36. Tubergen DG, Gilchrist GS, O'Brien RT, et al: Prevention of CNS disease in intermediate-risk acute lymphoblastic leukemia: Comparison of cranial radiation and intrathecal methotrexate and the importance of systemic therapy-A Children's Cancer Group report. J Clin Oncol 11:520-526, 1993

37. Jones B, Freeman Al, Shuster JJ, et al: Lower incidence of meningeal leukemia when prednisone is replaced by dexamethasone in the treatment of acute lymphocytic leukemia. Med Pediatr Oncol 19:269-275, 1991

38. Hijiya N, Hudson MM, Lensing S, et al: Cumulative incidence of secondary neoplasms as a first event after childhood acute lymphoblastic leukemia. JAMA 297:1207-1215, 2007

39. Neglia JP, Meadows AT, Robison LL, et al: Second neoplasms after acute lymphoblastic leukemia in childhood. N Engl J Med 325:1330-1336, 1991

40. Relling MV, Rubnitz JE, Rivera GK, et al: High incidence of secondary brain tumours after radiotherapy and antimetabolites. Lancet 354:34-39, 1999

41. Walter AW, Hancock ML, Pui $\mathrm{CH}$, et al: Secondary brain tumors in children treated for acute lymphoblastic leukemia at St Jude Children's Research Hospital. J Clin Oncol 16:3761-3767, 1998

42. Pui $\mathrm{CH}$, Behm FG, Raimondi SC, et al: Secondary acute myeloid leukemia in children treated for acute lymphoid leukemia. N Engl J Med 321:136-142, 1989

43. Pui $\mathrm{CH}$, Ribeiro RC, Hancock ML, et al: Acute myeloid leukemia in children treated with epipodophyllotoxins for acute lymphoblastic leukemia. N Engl J Med 325:1682-1687, 1991

44. Smith MA, Rubinstein L, Anderson JR, et al: Secondary leukemia or myelodysplastic syndrome after treatment with epipodophyllotoxins. J Clin Oncol 17:569-577, 1999

45. Winick N, Buchanan GR, Kamen BA: Secondary acute myeloid leukemia in Hispanic children. J Clin Oncol 11:1433, 1993

46. Winick NJ, McKenna RW, Shuster JJ, et al: Secondary acute myeloid leukemia in children with acute lymphoblastic leukemia treated with etoposide. J Clin Oncol 11:209-217, 1993

47. Krischer JP, Epstein S, Cuthbertson DD, et al: Clinical cardiotoxicity following anthracycline treatment for childhood cancer: The Pediatric Oncology Group experience. J Clin Oncol 15:1544-1552, 1997

48. Lipshultz SE, Colan SD, Gelber RD, et al: Late cardiac effects of doxorubicin therapy for acute lymphoblastic leukemia in childhood. N Engl J Med 324:808-815, 1991

49. Lipshultz SE, Lipsitz SR, Mone SM, et al: Female sex and drug dose as risk factors for late cardiotoxic effects of doxorubicin therapy for childhood cancer. N Engl J Med 332:1738-1743, 1995

50. Lipshultz SE, Lipsitz SR, Sallan SE, et al: Chronic progressive cardiac dysfunction years after doxorubicin therapy for childhood acute lymphoblastic leukemia. J Clin Oncol 23:2629-2636, 2005

51. Sorensen K, Levitt G, Bull C, et al: Anthracycline dose in childhood acute lymphoblastic leukemia: Issues of early survival versus late cardiotoxicity. J Clin Oncol 15:61-68, 1997

52. Barry EV, Vrooman LM, Dahlberg SE, et al: Absence of secondary malignant neoplasms in children with high-risk acute lymphoblastic leukemia treated with dexrazoxane. J Clin Oncol 26:1106-1111, 2008

53. Lipshultz SE, Giantris AL, Lipsitz SR, et al: Doxorubicin administration by continuous infusion is not cardioprotective: The Dana-Farber 91-01 Acute Lymphoblastic Leukemia protocol. J Clin Oncol 20:1677-1682, 2002

54. Lipshultz SE, Rifai N, Dalton VM, et al: The effect of dexrazoxane on myocardial injury in doxorubicin-treated children with acute lymphoblastic leukemia. N Engl J Med 351:145-153, 2004

55. Lefrak EA, Pitha J, Rosenheim S, et al: A clinicopathologic analysis of adriamycin cardiotoxicity. Cancer 32:302-314, 1973

56. Blanco JG, Sun CL, Landier W, et al: Anthracycline-related cardiomyopathy after childhood cancer: Role of polymorphisms in carbonyl reductase genes-A report from the Children's Oncology Group. J Clin Oncol 30:14151421,2012

57. Hudson MM, Rai SN, Nunez C, et al: Noninvasive evaluation of late anthracycline cardiac toxicity in childhood cancer survivors. J Clin Oncol 25:36353643, 2007

58. van der Pal HJ, van Dalen EC, van Delden E, et al: High risk of symptomatic cardiac events in childhood cancer survivors. J Clin Oncol 30:14291437, 2012

59. Hudson MM: Survivors of childhood cancer: Coming of age. Hematol Oncol Clin North Am 22:211-231, v-vi, 2008

60. Armstrong GT, Liu $Q$, Yasui $Y$, et al: Late mortality among 5-year survivors of childhood cancer: A summary from the Childhood Cancer Survivor Study. J Clin Oncol 27:2328-2338, 2009

61. Christensen MS, Heyman M, Möttönen M, et al: Treatment-related death in childhood acute lymphoblastic leukaemia in the Nordic countries: 1992-2001. Br J Haematol 131:50-58, 2005 
62. Mertens AC, Liu Q, Neglia JP, et al: Cause-specific late mortality among 5-year survivors of childhood cancer: The Childhood Cancer Survivor Study. J Natl Cancer Inst 100:1368-1379, 2008

63. Mody R, Li S, Dover DC, et al: Twenty-five-year follow-up among survivors of childhood acute lymphoblastic leukemia: A report from the Childhood Cancer Survivor Study. Blood 111:5515-5523, 2008

64. Pui $\mathrm{CH}$, Cheng $\mathrm{C}$, Leung $\mathrm{W}$, et al: Extended follow-up of long-term survivors of childhood acute lymphoblastic leukemia. N Engl J Med 349:640-649, 2003

65. Pui CH, Pei D, Sandlund JT, et al: Risk of adverse events after completion of therapy for childhood acute lymphoblastic leukemia. J Clin Oncol 23:79367941, 2005

66. Hudson MM, Mulrooney DA, Bowers DC, et al: High-risk populations identified in Childhood Cancer Survivor Study investigations: Implications for risk-based surveillance. J Clin Oncol 27:2405-2414, 2009

67. Armstrong GT, Reddick WE, Petersen RC, et al: Evaluation of memory impairment in aging adult survivors of childhood acute lymphoblastic leukemia treated with cranial radiotherapy. J Natl Cancer Inst 105:899-907, 2013

68. Kadan-Lottick NS, Brouwers $P$, Breiger D, et al: Comparison of neurocognitive functioning in children previously randomly assigned to intrathecal methotrexate compared with triple intrathecal therapy for the treatment of childhood acute lymphoblastic leukemia. J Clin Oncol 27:5986-5992, 2009

69. Krull KR, Bhojwani D, Conklin HM, et al: Genetic mediators of neurocognitive outcomes in survivors of childhood acute lymphoblastic leukemia. J Clin Oncol 31:2182-2188, 2013

70. Krull KR, Zhang N, Santucci A, et al: Long-term decline in intelligence among adult survivors of childhood acute lymphoblastic leukemia treated with cranial radiation. Blood 122:550-553, 2013

71. Schuitema I, Deprez S, Van Hecke W, et al: Accelerated aging, decreased white matter integrity, and associated neuropsychological dysfunction 25 years after pediatric lymphoid malignancies. J Clin Oncol 31:3378-3388, 2013

72. Jones TS, Kaste SC, Liu W, et al: CRHR1 polymorphisms predict bone density in survivors of acute lymphoblastic leukemia. J Clin Oncol 26:3031-3037, 2008

73. Kadan-Lottick NS, Dinu I, Wasilewski-Masker K, et al: Osteonecrosis in adult survivors of childhood cancer: A report from the childhood cancer survivor study. J Clin Oncol 26:3038-3045, 2008

74. Karimova EJ, Rai SN, Howard SC, et al: Femoral head osteonecrosis in pediatric and young adult patients with leukemia or lymphoma. J Clin Oncol 25:1525-1531, 2007

75. Kaste SC, Chesney RW, Hudson MM, et al: Bone mineral status during and after therapy of childhood cancer: An increasing population with multiple risk factors for impaired bone health. J Bone Miner Res 14:2010-2014, 1999

76. Kaste SC, Jones-Wallace D, Rose SR, et al: Bone mineral decrements in survivors of childhood acute lymphoblastic leukemia: Frequency of occurrence and risk factors for their development. Leukemia 15:728-734, 2001

77. Kaste SC, Rai SN, Fleming K, et al: Changes in bone mineral density in survivors of childhood acute lymphoblastic leukemia. Pediatr Blood Cancer 46:77-87, 2006

78. Mandel K, Atkinson S, Barr RD, et al: Skeletal morbidity in childhood acute lymphoblastic leukemia. J Clin Oncol 22:1215-1221, 2004

79. Mattano LA Jr, Sather HN, Trigg ME, et al: Osteonecrosis as a complication of treating acute lymphoblastic leukemia in children: A report from the Children's Cancer Group. J Clin Oncol 18:3262-3272, 2000

80. Niinimäki RA, Harila-Saari $A H$, Jartti $A E$, et al: High body mass index increases the risk for osteonecrosis in children with acute lymphoblastic leukemia. J Clin Oncol 25:1498-1504, 2007

81. Relling $M V$, Yang $W$, Das $S$, et al: Pharmacogenetic risk factors for osteonecrosis of the hip among children with leukemia. J Clin Oncol 22:39303936, 2004

82. Strauss AJ, Su JT, Dalton VM, et al: Bony morbidity in children treated for acute lymphoblastic leukemia. J Clin Oncol 19:3066-3072, 2001

83. te Winkel ML, Pieters R, Hop WC, et al: Prospective study on incidence, risk factors, and long-term outcome of osteonecrosis in pediatric acute lymphoblastic leukemia. J Clin Oncol 29:4143-4150, 2011

84. Oeffinger KC, Adams-Huet B, Victor RG, et al: Insulin resistance and risk factors for cardiovascular disease in young adult survivors of childhood acute lymphoblastic leukemia. J Clin Oncol 27:3698-3704, 2009

85. Oeffinger KC, Mertens AC, Sklar CA, et al: Obesity in adult survivors of childhood acute lymphoblastic leukemia: A report from the Childhood Cancer Survivor Study. J Clin Oncol 21:1359-1365, 2003

86. Visscher H, Ross CJ, Rassekh SR, et al: Pharmacogenomic prediction of anthracycline-induced cardiotoxicity in children. J Clin Oncol 30:1422-1428, 2012
87. Schmiegelow K, Levinsen MF, Attarbaschi A, et al: Second malignant neoplasms after treatment of childhood acute lymphoblastic leukemia. J Clin Oncol 31:2469-2476, 2013

88. Evans WE, Crom WR, Abromowitch M, et al: Clinical pharmacodynamics of high-dose methotrexate in acute lymphocytic leukemia: Identification of a relation between concentration and effect. N Engl J Med 314:471-477, 1986

89. Evans WE, Relling MV, Rodman JH, et al: Conventional compared with individualized chemotherapy for childhood acute lymphoblastic leukemia. N Engl J Med 338:499-505, 1998

90. Kremer LC, Mulder RL, Oeffinger KC, et al: A worldwide collaboration to harmonize guidelines for the long-term follow-up of childhood and young adult cancer survivors: A report from the International Late Effects of Childhood Cancer Guideline Harmonization Group. Pediatr Blood Cancer 60:543-549, 2013

91. Landier W, Bhatia S, Eshelman DA, et al: Development of risk-based guidelines for pediatric cancer survivors: The Children's Oncology Group LongTerm Follow-Up Guidelines from the Children's Oncology Group Late Effects Committee and Nursing Discipline. J Clin Oncol 22:4979-4990, 2004

92. Hudson MM, Ness KK, Gurney JG, et al: Clinical ascertainment of health outcomes among adults treated for childhood cancer. JAMA 309:2371-2381, 2013

93. Landier W, Armenian SH, Lee J, et al: Yield of screening for long-term complications using the Children's Oncology Group long-term follow-up guidelines. J Clin Oncol 30:4401-4408, 2012

94. Lipshultz SE, Lipsitz SR, Sallan SE, et al: Long-term enalapril therapy for left ventricular dysfunction in doxorubicin-treated survivors of childhood cancer. $\mathrm{J}$ Clin Oncol 20:4517-4522, 2002

95. Silber JH, Cnaan A, Clark BJ, et al: Enalapril to prevent cardiac function decline in long-term survivors of pediatric cancer exposed to anthracyclines. J Clin Oncol 22:820-828, 2004

96. Jansen NC, Kingma A, Schuitema A, et al: Neuropsychological outcome in chemotherapy-only-treated children with acute lymphoblastic leukemia. J Clin Oncol 26:3025-3030, 2008

97. Spiegler BJ, Kennedy K, Maze R, et al: Comparison of long-term neurocognitive outcomes in young children with acute lymphoblastic leukemia treated with cranial radiation or high-dose or very high-dose intravenous methotrexate. $\mathrm{J}$ Clin Oncol 24:3858-3864, 2006

98. Waber DP, Turek J, Catania L, et al: Neuropsychological outcomes from a randomized trial of triple intrathecal chemotherapy compared with $18 \mathrm{~Gy}$ cranial radiation as CNS treatment in acute lymphoblastic leukemia: Findings from Dana-Farber Cancer Institute ALL Consortium Protocol 95-01. J Clin Oncol 25:4914-4921, 2007

99. Conklin HM, Reddick WE, Ashford J, et al: Long-term efficacy of methylphenidate in enhancing attention regulation, social skills, and academic abilities of childhood cancer survivors. J Clin Oncol 28:4465-4472, 2010

100. Mulhern RK, Khan RB, Kaplan S, et al: Short-term efficacy of methylphenidate: A randomized, double-blind, placebo-controlled trial among survivors of childhood cancer. J Clin Oncol 22:4795-4803, 2004

101. Ambros PF, Ambros IM, Brodeur GM, et al: International consensus for neuroblastoma molecular diagnostics: Report from the International Neuroblastoma Risk Group (INRG) Biology Committee. Br J Cancer 100:1471-1482, 2009

102. Cohn SL, Pearson AD, London WB, et al: The International Neuroblastoma Risk Group (INRG) classification system: An INRG Task Force report. J Clin Oncol 27:289-297, 2009

103. Ellison DW, Kocak M, Dalton J, et al: Definition of disease-risk stratification groups in childhood medulloblastoma using combined clinical, pathologic, and molecular variables. J Clin Oncol 29:1400-1407, 2011

104. Vardiman JW, Thiele J, Arber DA, et al: The 2008 revision of the World Health Organization (WHO) classification of myeloid neoplasms and acute leukemia: Rationale and important changes. Blood 114:937-951, 2009

105. Sandlund JT: Should adolescents with NHL be treated as old children or young adults? Hematology Am Soc Hematol Educ Program 2007:297-303, 2007

106. Grundy PE, Breslow NE, Li S, et al: Loss of heterozygosity for chromosomes $1 p$ and $16 q$ is an adverse prognostic factor in favorable-histology Wilms tumor: A report from the National Wilms Tumor Study Group. J Clin Oncol 23:7312-7321, 2005

107. Breneman JC, Lyden E, Pappo AS, et al: Prognostic factors and clinical outcomes in children and adolescents with metastatic rhabdomyosarcoma: A report from the Intergroup Rhabdomyosarcoma Study IV. J Clin Oncol 21:78-84, 2003

108. Raney RB, Anderson JR, Barr FG, et al: Rhabdomyosarcoma and undifferentiated sarcoma in the first two decades of life: A selective review of intergroup rhabdomyosarcoma study group experience and rationale for Intergroup Rhabdomyosarcoma Study V. J Pediatr Hematol Oncol 23:215-220, 2001 
109. Brown P, Small D: FLT3 inhibitors: A paradigm for the development of targeted therapeutics for paediatric cancer. Eur J Cancer 40:707-721; discussion 722-724, 2004

110. DuBois SG, Marina N, Glade-Bender J: Angiogenesis and vascular targeting in Ewing sarcoma: A review of preclinical and clinical data. Cancer 116:749757,2010

111. Thiele CJ, Li Z, McKee AE: On Trk-the TrkB signal transduction pathway is an increasingly important target in cancer biology. Clin Cancer Res 15:59625967, 2009

112. $Y u$ AL, Gilman AL, Ozkaynak MF, et al: Anti-GD2 antibody with GM-CSF, interleukin-2, and isotretinoin for neuroblastoma. N Engl J Med 363:1324-1334, 2010

113. Bautista F, Paci A, Minard-Colin V, et al: Vemurafenib in pediatric patients with BRAFV600E mutated high-grade gliomas. Pediatr Blood Cancer [epub ahead of print on December 3, 2013]

114. Fox E, Widemann BC, Chuk MK, et al: Vandetanib in children and adolescents with multiple endocrine neoplasia type 2B associated medullary thyroid carcinoma. Clin Cancer Res 19:4239-4248, 2013

115. Mossé YP, Lim MS, Voss SD, et al: Safety and activity of crizotinib for paediatric patients with refractory solid tumours or anaplastic large-cell lymphoma: A Children's Oncology Group phase 1 consortium study. Lancet Oncol $14: 472-480,2013$
116. National Cancer Institute: A snapshot of pediatric cancers. http://www .cancer.gov/researchandfunding/snapshots/pediatric

117. French D, Hamilton LH, Mattano LA Jr, et al: A PAI-1 (SERPINE1) polymorphism predicts osteonecrosis in children with acute lymphoblastic leukemia: A report from the Children's Oncology Group. Blood 111:4496-4499, 2008

118. Kawedia JD, Kaste SC, Pei D, et al: Pharmacokinetic, pharmacodynamic, and pharmacogenetic determinants of osteonecrosis in children with acute lymphoblastic leukemia. Blood 117:2340-2347, 2011

119. Relling MV, Yanishevski Y, Nemec J, et al: Etoposide and antimetabolite pharmacology in patients who develop secondary acute myeloid leukemia. Leukemia 12:346-352, 1998

120. Ross JA, Oeffinger KC, Davies SM, et al: Genetic variation in the leptin receptor gene and obesity in survivors of childhood acute lymphoblastic leukemia: A report from the Childhood Cancer Survivor Study. J Clin Oncol 22:35583562, 2004

121. Wang $X$, Liu $W$, Sun $C L$, et al: Hyaluronan synthase 3 variant and anthracycline-related cardiomyopathy: A report from the Children's Oncology Group. J Clin Oncol 32:647-653, 2014

DOI: $10.1200 / J C O .2014 .55 .6571$; published online ahead of print at www.jco.org on April 14, 2014 


\section{Acknowledgment}

Supported by the American Lebanese Syrian Associated Charities and National Institute of Health Cancer Support Grant No. P30 CA 21765 (M.M.H.). 